\title{
The earliest evidence of pattern looms: Han Dynasty tomb models from Chengdu, China
}

Feng Zhao ${ }^{1,2,3, *}$, Yi Wang ${ }^{4}$, Qun Luo ${ }^{1,2}$, Bo Long ${ }^{1,2}$, Baichun Zhang ${ }^{5}$, Yingchong $\mathrm{Xia}^{6}$, Tao Xie ${ }^{4}$, Shunqing $\mathrm{Wu}^{7}$ $\&$ Lin $\mathrm{Xiao}^{4}$

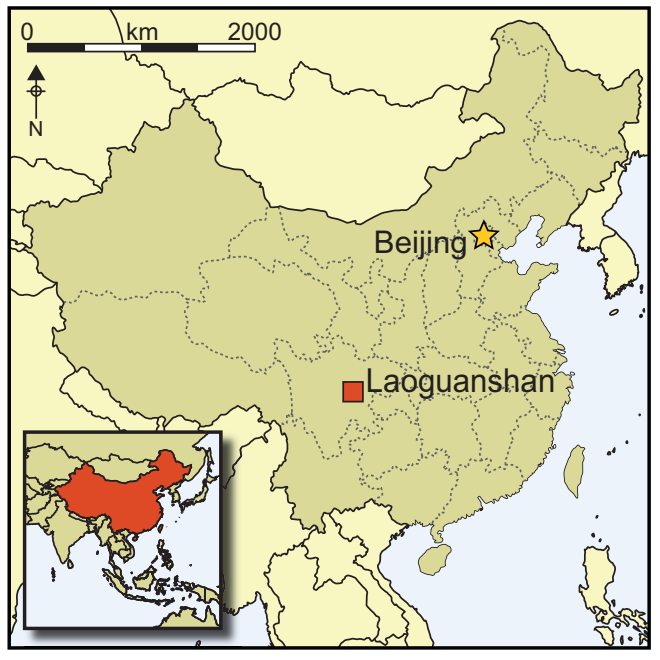

Excavation of the Han Dynasty chambered tomb at Laoguanshan in Chengdu, southwest China, has provided the earliest known evidence of pattern loom technology. Four model looms, along with accompanying artefacts and figurines relating to the weaving process, give insight into the technique of jin silk production. The discovery is hugely significant as it provides the first direct evidence of pattern-weave textile production in ancient China. Jin silk, made using this method, was both valuable and widely distributed, and the design of the machine influenced the invention of later looms and the spread of technology throughout Eurasia and Europe, representing great technological accomplishment for the second century $B C$.

Keywords: China, Han Dynasty, pattern loom, woven silk, textile workshop

\section{Introduction}

As one of the important luxury products of early China, discoveries of silk, and evidence of the weaving technology used in the production of silk textiles, are of great significance. New light has been thrown on this technology by the discovery, in 2013, of an exceptional find:

China National Silk Museum, 73-1 Yuhuangshan Road, Hangzhou 310002, PR China

2 Key Scientific Research Base of Textile Conservation, State Administration of Cultural Heritage, 73-1 Yuhuangshan Road, Hangzhou 310002, PR China

3 Donghua University, 1882 West Yan'an Road, Shanghai 200051, PR China

Chengdu Museum, 18 Shierqiao Road, Chengdu 610072, PR China

5 Institute for the History of Natural Sciences, Chinese Academy of Sciences, 55 Zhongguancun East Road, Beijing 100190, PR China

6 Zhijiang College of Zhejiang University of Technology, 182 Zhijiang Road, Hangzhou 310024, PR China

7 Jinzhou Conservation Center for Cultural Heritage, 142 Jingzhong Road, Jingzhou 434100, PR China

* Author for correspondence (Email: zhaofeng@dhu.edu.cn) 
four wooden models of pattern looms, and associated figurines and paraphernalia from a model textile workshop, excavated from a Han Dynasty burial at Laoguanshan, Chengdu, south-west China. These date to the second half of the second century $\mathrm{BC}$, and are the earliest evidence for the use of pattern looms in China (Chengdu Institute of Archaeology $\&$ Jinzhou Conservation Center for Cultural Heritage 2014). Their discovery points to an ancient Chinese origin for a technology that revolutionised silk production throughout the rest of Asia and Europe.

Laoguanshan is located in the northern part of the Chengdu municipality in Sichuan province. This was part of the ancient kingdom of Shu, which was a classical production centre for jin silk (a polychrome woven textile) in early times from the Qin to Tang Dynasties (second century BC to ninth century AD). It had good connections with northwest China, and it was via this route that the jin silk was exported to the Silk Road.

A pattern loom is a weaving device with a set of shafts with heddles (or harnesses-a glossary of terms used throughout the article is included at the end of the text) that allow a pattern programme to be installed and used to create continuous repeating patterns. The Chinese word for loom, chi (or $j i)$, represents the outline of a loom and embodies the ancient Chinese concept of technology and machinery par excellence (Needham 1988). The loom plays a vital role in the history of Chinese textiles, but also in the global history of science and technology. Until 2014, however, our knowledge of the early history of the pattern loom was limited to textual references and excavated patterned textiles. The pattern loom models excavated from Laoguanshan document, for the first time, the early history of this technology in artefact form. The loom models are thus key to the technology of silk pattern weaving. Moreover, and unexpectedly, they testify to the very advanced weaving technology of the treadle loom in East Asia as early as the second century BC, a technology that was not known in the West until a millennium later.

\section{The Laoguanshan discovery}

Four model pattern looms, with devices for warping, rewinding and weft winding, were found in tomb two at Laoguanshan, along with 15 painted wooden figurines, each with their name written on the breast and probably representing weavers or weaving-related workers (Figure 1). The size of the whole set, including loom and accompanying weaver figurines, is approximately one-sixth that of life size.

The tomb chamber, which is $7.2 \mathrm{~m}$ long, $4.5 \mathrm{~m}$ wide and $2.75 \mathrm{~m}$ high, was made of painted wood and consists of five compartments, one large component on the top and four smaller ones below. The uppermost compartment contained a coffin with a female corpse, around 50 years old at death. According to a jade seal found broken outside the coffin (suggesting that the tomb had been robbed just after burial), the individual was named 'Wan Dinu'. The small compartment below contained the four model pattern looms, while the other chests held numerous lacquer objects (Figure 2). From the tomb style and the discovery of a Western Han bronze coin, the chamber was dated to the reigns of Emperors Jingdi (157-141 BC) and Wudi (141-88 BC) of the Western Han Dynasty. No ${ }^{14} \mathrm{C}$ dating has yet been undertaken. 


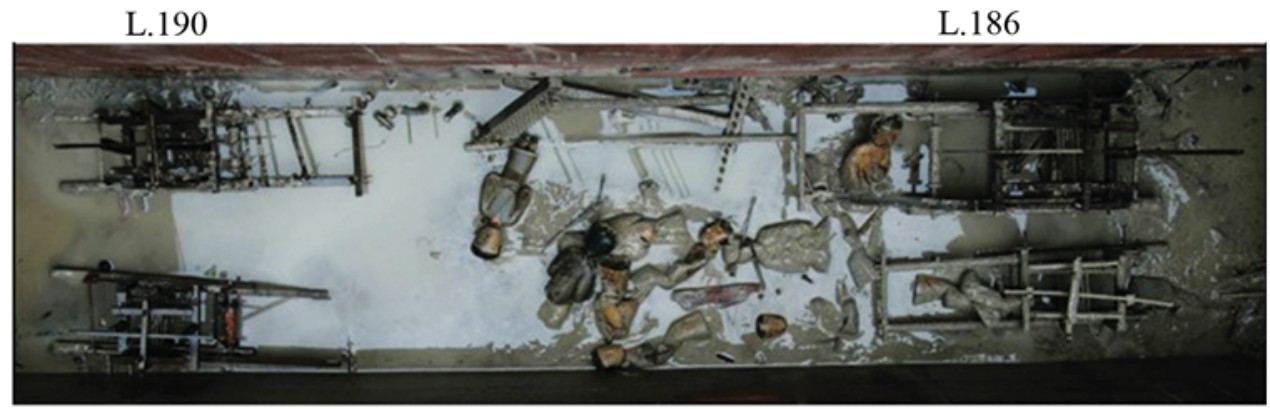

L.191

L.189

Figure 1. The compartment with the four model looms photographed during excavation (photograph by Tao Xie).

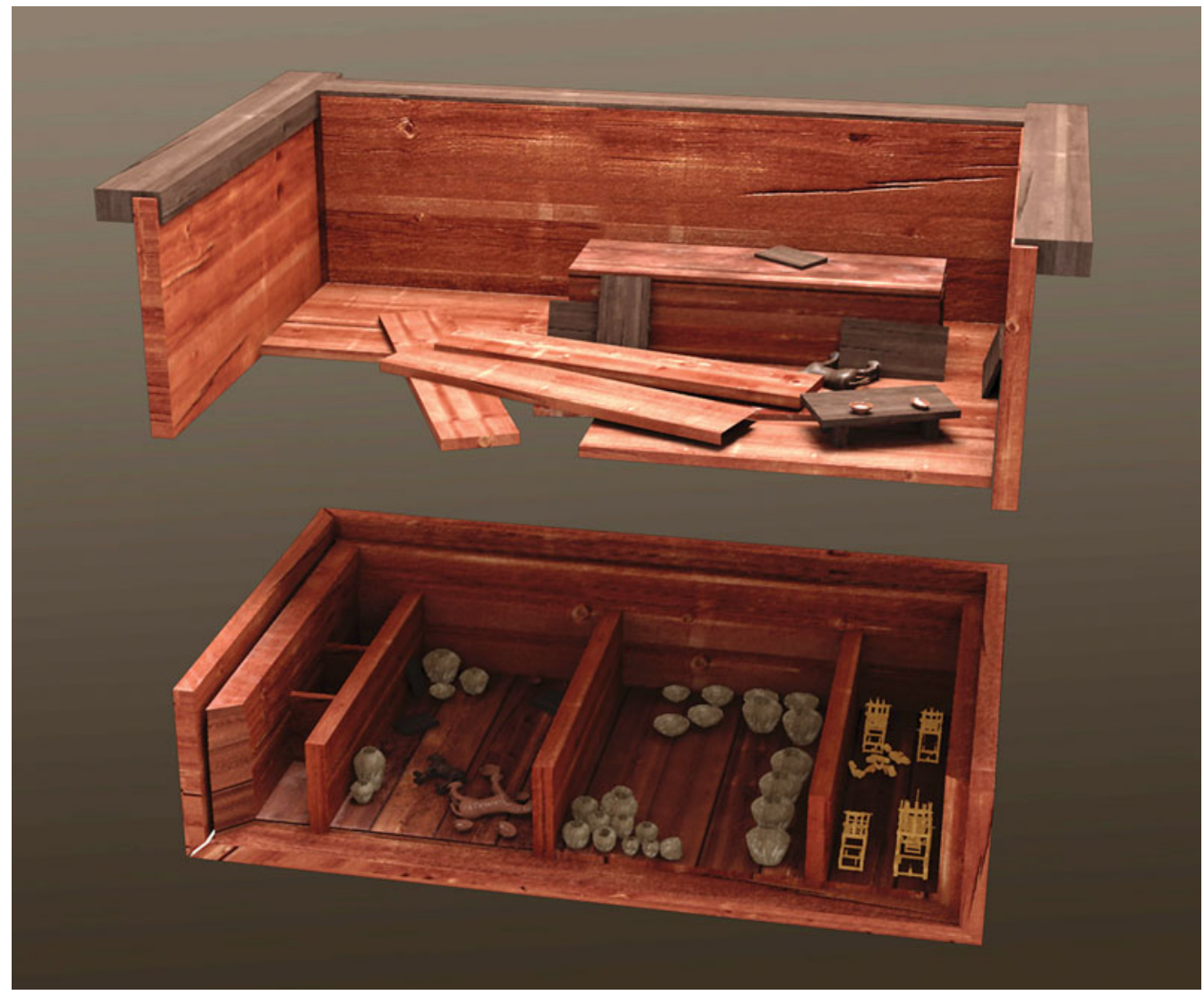

Figure 2. A reconstruction of the tomb chamber showing the four compartments (a single larger compartment above and three smaller ones below) (drawing by Yingchong Xia).

The four loom models were made mainly of wood and partly of bamboo, with cinnabardyed silk threads preserved on the beams. Loom 186 is the largest model, with dimensions of $0.85 \mathrm{~m}$ long, $0.26 \mathrm{~m}$ wide and $0.5 \mathrm{~m}$ high, while the others, L. 189 , L.190 and L.191, are smaller (Figure 3; Table 1).

(C) Antiquity Publications Ltd, 2017 
Table 1. Dimensions of the four loom models found in the chambered tomb at Laoguanshan.

\begin{tabular}{llllccrr}
\hline $\begin{array}{l}\text { Loom } \\
\text { no. }\end{array}$ & $\begin{array}{l}\text { Location } \\
\text { in chest }\end{array}$ & $\begin{array}{l}\text { Dimensions } \\
(\mathbf{m m})\end{array}$ & $\begin{array}{l}\text { Power } \\
\text { transmission }\end{array}$ & $\begin{array}{c}\text { Grille } \\
\text { compartments }\end{array}$ & $\begin{array}{c}\text { Pattern } \\
\text { shafts }\end{array}$ & $\begin{array}{c}\text { Foundation } \\
\text { shafts }\end{array}$ & $\begin{array}{c}\text { Real } \\
\text { dimensions }(\mathbf{m})\end{array}$ \\
\hline & & & & & & & \\
186 & north-east & L850, W260, H500 & sliding frame & 19 & 5 & 2 & L5.10, W1.56, H3.00 \\
189 & south-east & L670, W196, H360 & hook rod & 13 & 3 & 2 & L4.02, W1.18, H2.16 \\
190 & north-west & L640, W190, H370 & hook rod & 12 & 3 & L3.84, W1.14, H2.22 \\
191 & south-west & L630, W190, H360 & hook rod & 12 & 5 & L3.78, W1.14, H2.16 \\
\hline
\end{tabular}




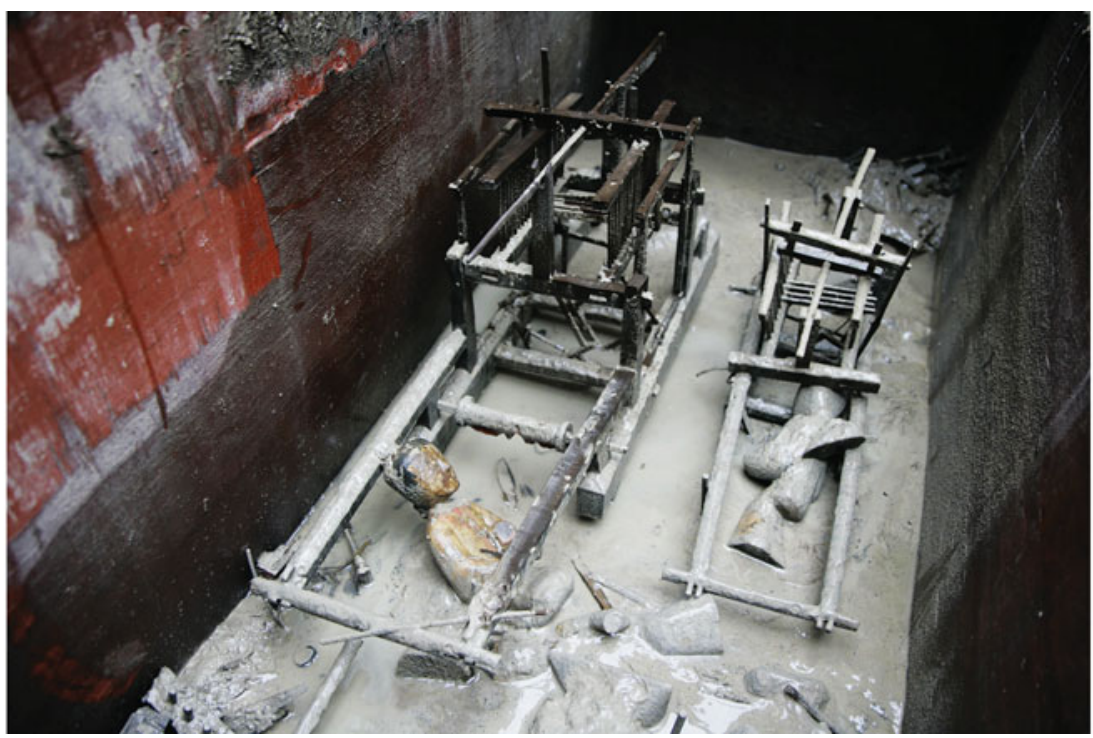

Figure 3. L.186 (left) and L.189 (right) photographed during excavation (photograph by Tao Xie).

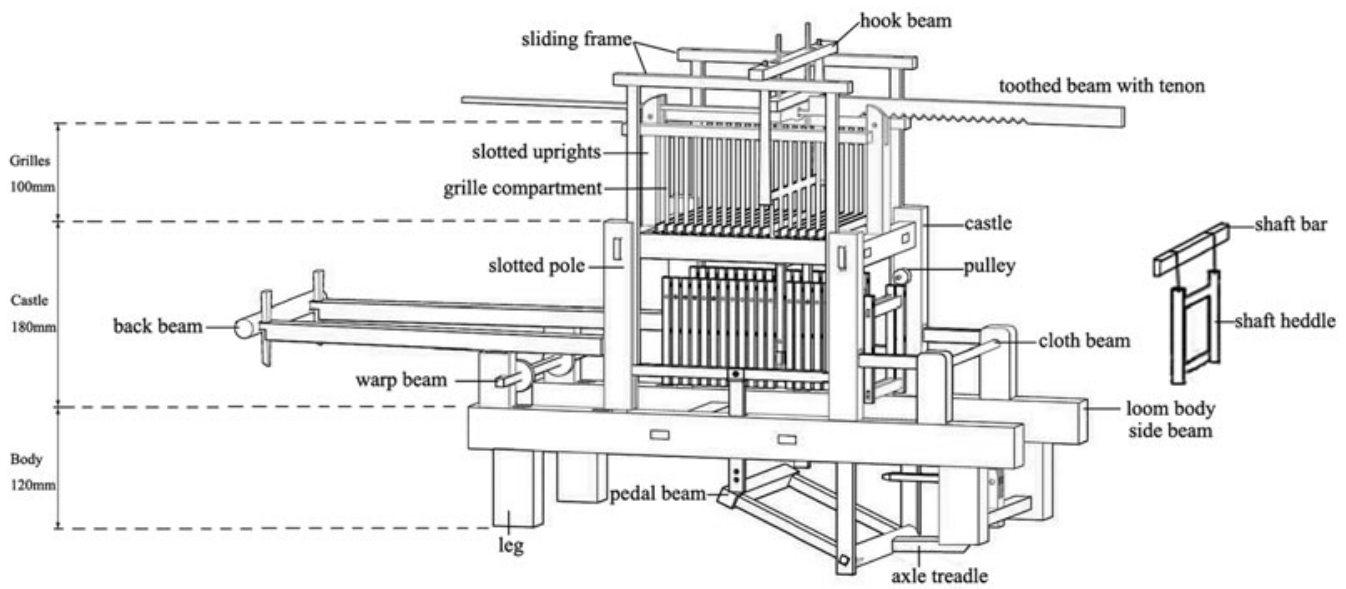

Figure 4. Labelled schematic showing the design and components of L.186 (drawing by Bo Long).

Although all four models collapsed after removal from the burial, all of the constituent elements were preserved and the looms could be reconstructed.

\section{Loom L.186.}

Our reconstruction of L.186, the largest of the models, indicates a loom body $550 \mathrm{~mm}$ long, $240 \mathrm{~mm}$ wide and $120 \mathrm{~mm}$ tall, supported by four legs, on which stands a loom castle, $250 \mathrm{~mm}$ long, $230 \mathrm{~mm}$ wide and $180 \mathrm{~mm}$ tall, made of four slotted poles. Two $100 \mathrm{~mm}$-high grilles made of bamboo, each with 19 compartments, stand on either side of the loom castle to contain the pattern shafts (Figures $4 \& 5$ ).

(C) Antiquity Publications Ltd, 2017 


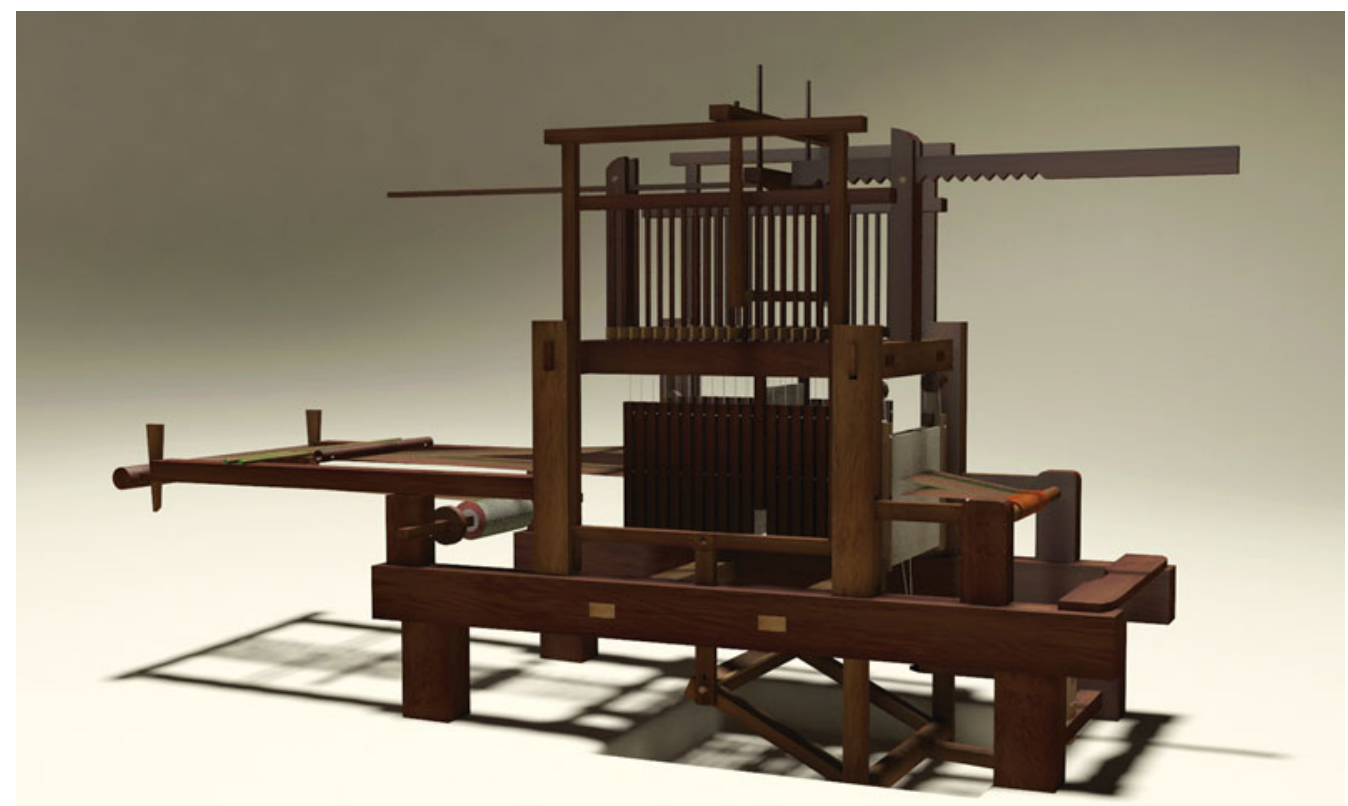

Figure 5. A reconstruction of loom model L.186 (drawing by Bo Long and Yingchong Xia).

The warp beam and cloth beam stretch the warp on the loom, the former at the back to hold the warp, and the latter at the front to hold the cloth. They are both supported by two pairs of struts, $67 \mathrm{~mm}$ high, with a ratchet on the right-hand side. A back beam (240mm long), or 'whip roll', is placed on an extra frame, at the back of the loom to accommodate a longer warp on the loom and adjust change when the shed is made (Figure 6).

The foundation shafts create the warp's natural and counter sheds, enabling the shuttle to pass and weave a tabby structure. On the inner sides of the two front slotted poles of the loom castle, there is one pair of pulleys, with two foundation shafts, about $100 \mathrm{~mm}$ high and $95 \mathrm{~mm}$ wide, which are operated by two treadles on the pedal beam.

The pattern shafts installed in the loom castle are the most complex system components in this particular loom type, but, unfortunately, there are only five pattern shafts left. Each hangs by a shaft bar, $158 \mathrm{~mm}$ long, among 19 total loom castle grille compartments. The 14 vacant grille compartments enforce the idea that, in this regard, the loom model was only an imitation of a real pattern loom. During the weaving process, one side of the axle treadle held by the front poles is depressed, raising the other side upwards in order to push two sliding frames in the slotted poles upwards. Then the hook beam on the top is also pushed up by two sliding frames (Figure 4), lifting a shaft bar in a certain compartment, and thereafter lifting a corresponding shaft. To select the desired shafts, a toothed beam with two tenons carrying the hook beam and moving in the direction of the warp can be stopped at a certain position to select a particular pattern shaft. This selecting of pattern shafts could be performed by the weaver or their assistant. 


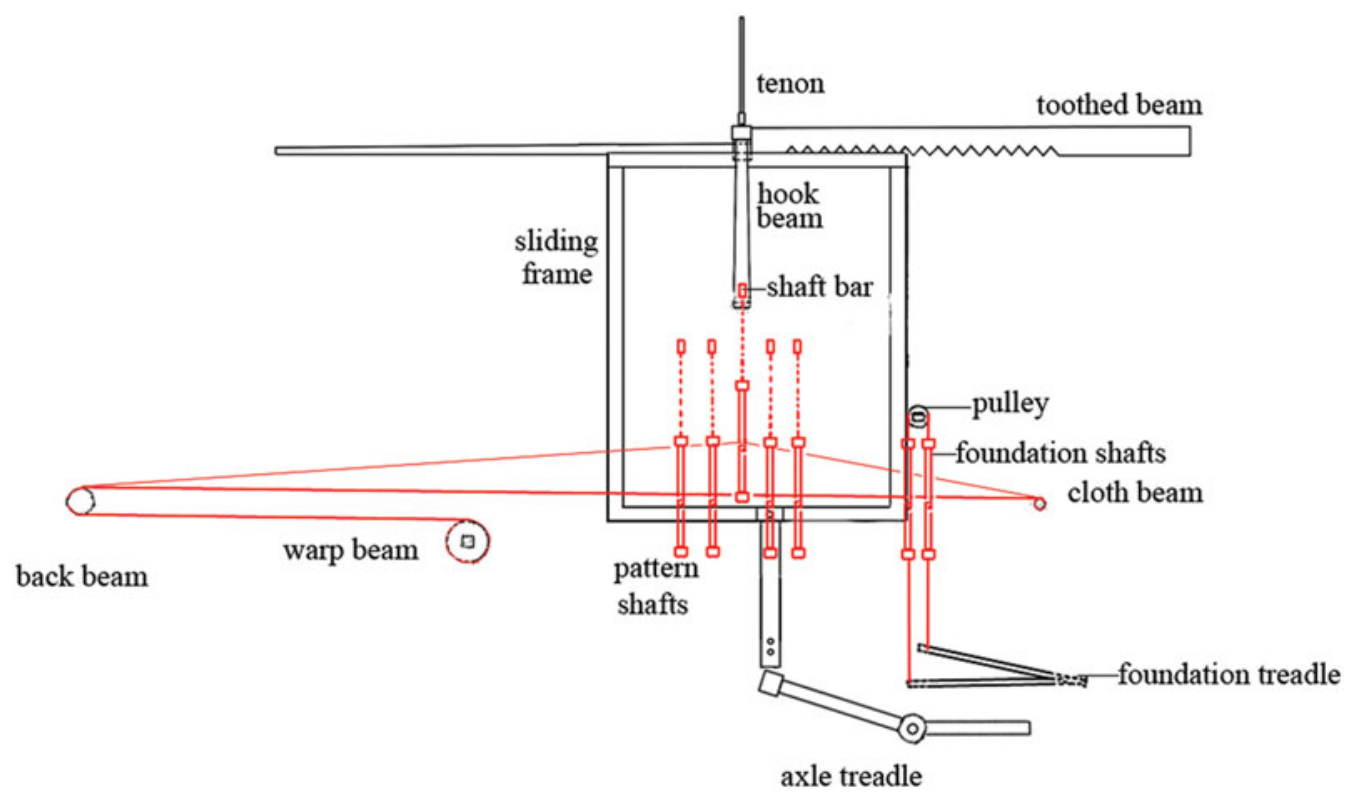

Figure 6. Model showing the movement of the beams, shafts and treadles of L.186. Red markings indicate the moving warp and shaft components of the loom (drawing by Feng Zhao and Bo Long).

\section{Looms L.189, L.190 and L.191: pattern looms with hook rods}

The other three models are smaller than L.186. Their operating system is also different from L.186, with two hook rods on both sides, instead of two sliding frames and a hook beam to lift the shaft bar. When the weaver steps on one side of the axle treadle, the other side pushes the hook rods upwards, and the hooks lift the shaft bar and the pattern shaft. These models constitute the earliest evidence of such a linkage mechanism in Chinese weaving technology (Figure 7 compares the means of power transmission for L.186 and L.189).

We therefore suggest a new terminology for these two types of pattern loom models. As a group, they may be described as 'hook-shaft pattern looms', with the former type being a hook-shaft pattern loom with sliding frames (L.186), and the latter types being hook-shaft pattern looms with hook rods.

\section{Han Dynasty jin silk}

No textiles were found on the looms; indeed, no silk textiles from this period have been discovered so far in this area of China. So-called jin silk (Zhao 1999), dating to the previous Warring States period (fifth-third centuries BC) and the Early Han Dynasty (second-first centuries BC), has been excavated from other regions. All these excavated jin silks used the same weave structure: warp-faced compound tabby, a particular, traditional weave structure originating from ancient China. The preservation of red silk thread coloured by cinnabar, and brown silk thread on the Laoguanshan models, strongly suggests that looms with multiple shafts were used to weave textiles similar to those from Mawangdui at Changsha, in Hunan province, and Fenghuangshan at Jinzhou, in Hubei province. These have geometric (C) Antiquity Publications Ltd, 2017 

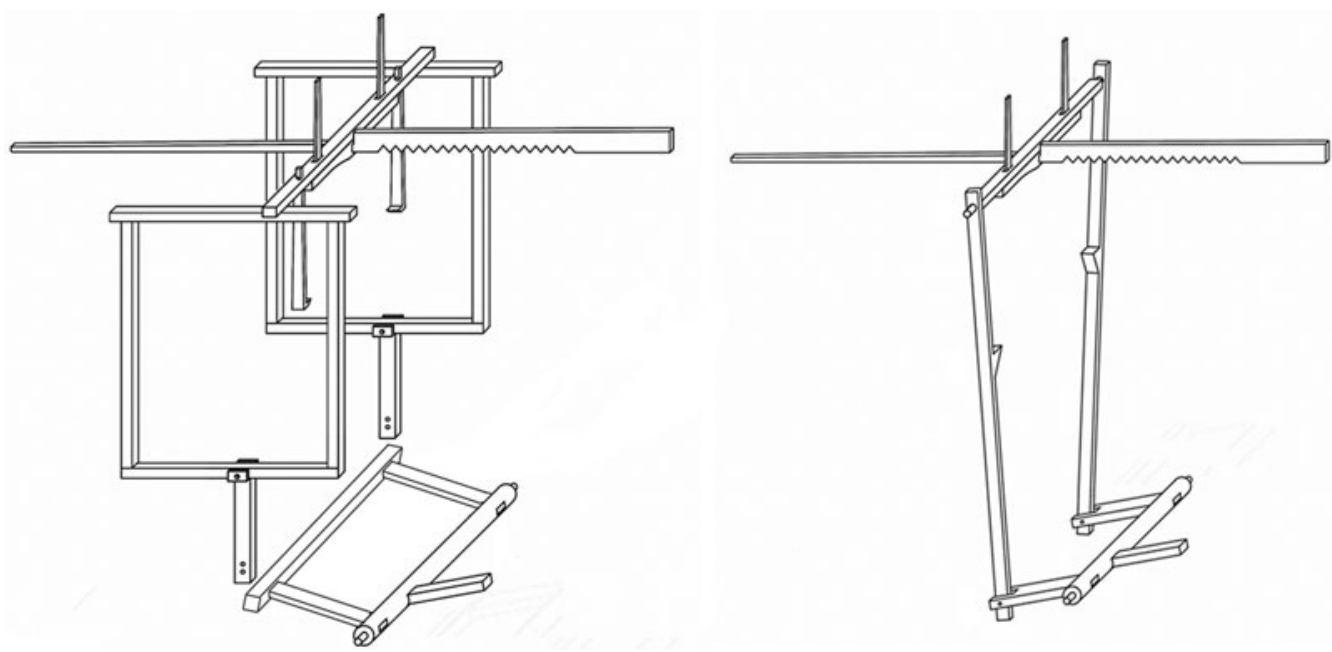

Figure 7. Diagram comparing the modes of power used for models L.186 (left) and L.189 (right) (drawing by Qun Luo).
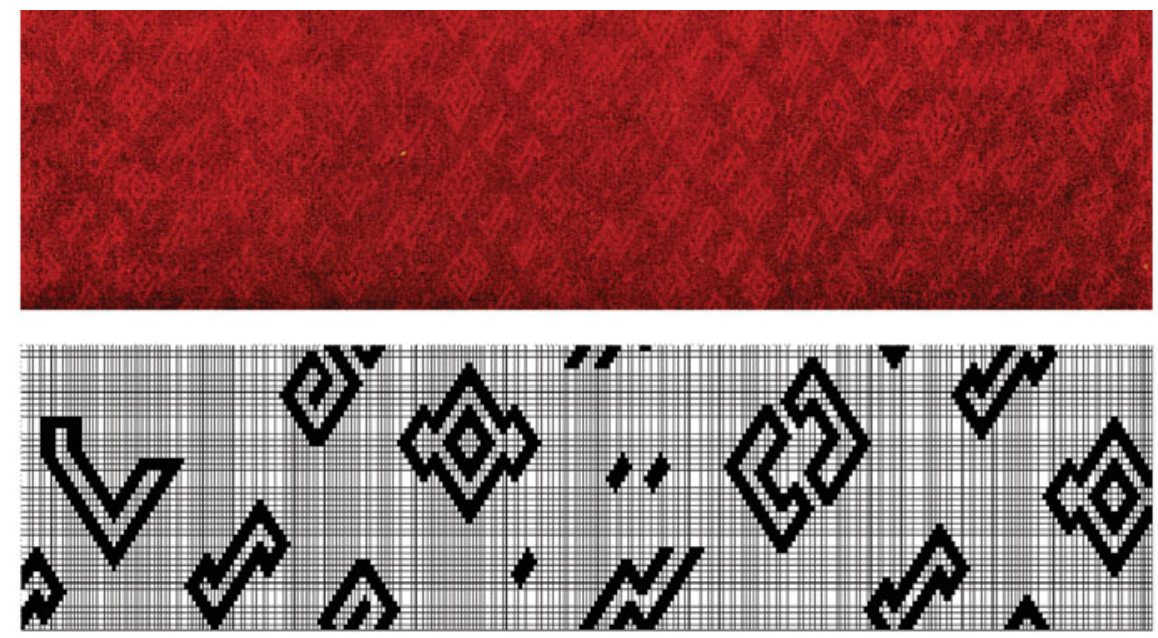

Figure 8. Geometric-patterned jin silk from Mawangdui and accompanying design plan of the corresponding pattern (drawing by Jialiang $L u$ ).

patterns (Figure 8), with bird motifs at Mawangdui (The Archaeological Research Group of the Shanghai Textile Research Institute and the Shanghai Silk Industry Corporation 1980), and leopard motifs at Fenghuangshan (Chen 1993). Both are dated to the second century BC.

All the jin silks from this period, including those from these loom models, were probably made using a similar technique (warp silk yarn was dyed before being woven) and weave structure: warp-faced compound tabby (Figure 9). To weave red and brown jin silk, both coloured warps were grouped together and entered one heddle of two foundation shafts in an alternating order. Each group of warps should select either red or brown warp to enter 
one heddle of every pattern shaft according to the particular design. Thus, when one pattern shaft is lifted, each heddle should lift either red or brown warp to form the design. Below, we use the jin silk with geometric pattern as an example for 2 foundational shafts and 24 pattern shafts to weave on the loom (Figure 10).

\section{Pattern-loom operating system}

A shed is formed by two layers of warps, one lifted and the other depressed, to allow the weft to pass through. Four sheds should be formed, step by step, to carry out a weave unit.

- Shed one for foundation: the foundation treadle one is depressed and foundational shaft two is lifted; the tabby shed is formed, and the shuttle with foundation weft passes through.

- Shed two for pattern: the pattern treadle is depressed to push the sliding frame up. Pattern shaft one is lifted to make a shed for the weft because the hook beam is moved with the toothed beam to the position of pattern shaft one.

- Shed three for foundation: foundation treadle two is depressed and foundation shaft one is lifted.

- Shed four for pattern: the hook beam is moved to pattern shaft two, then the pattern treadle is depressed and pattern shaft two is lifted.

Following on from this sequence, foundation shaft one lifts again for shed five, pattern shaft three for shed six, foundation shaft two for shed seven and pattern shaft four for

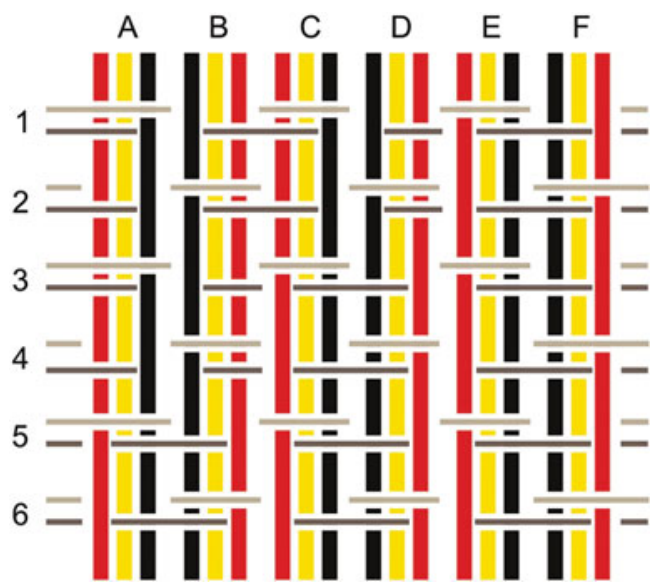

Figure 9. The warp-faced compound tabby used for the creation of jin silk, with different coloured warps shown. Numbers refer to two series of wefts, one of which appears on the face while the other is on the reverse. Letters refer to the sets of warps (drawing by Le Wang). shed eight, until pattern shaft twenty-four is lifted for shed forty-eight, which marks the end of one weave repetition. After the first sequence is finished, the pattern plan could be repeated from 1-24 or reversed from 24-1. In this particular case, for a geometric pattern, it would be started again from 1-24 (Figure 11).

\section{Discussion}

Looms, loom models, component pieces and illustrations of weaving technology have come to light through archaeological excavations around the world. These include: the horizontal two-bar loom in the model of a weaving workshop from the tomb of Meket-Re in Egypt (Ninth Dynasty, c. $2000 \mathrm{BC}$ ); the vertical loom illustrated in the tomb of Thot-nefer at Thebes (Eighteenth Dynasty, c. 1425 BC) (Broudy 1979); the warp-weighted loom illustrated in Greek vase paintings of the fifth and fourth centuries $\mathrm{BC}$; and finds of loom (C) Antiquity Publications Ltd, 2017 


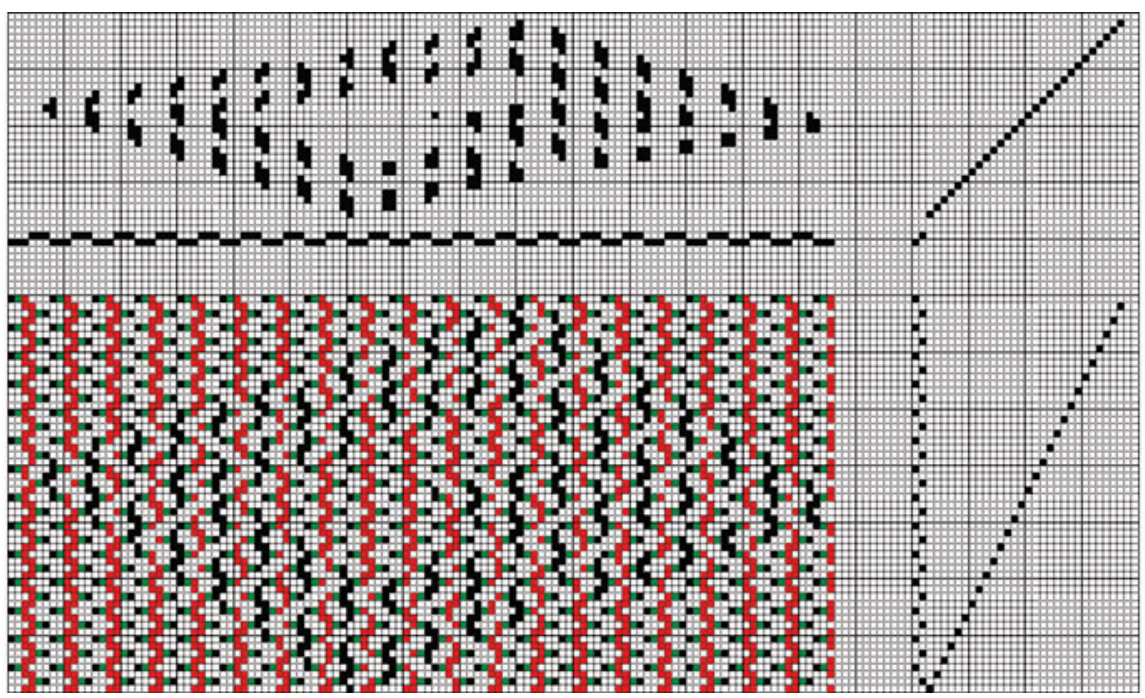

Figure 10. An example of a weaving plan for jin silk with a geometric pattern (drawing by Jialiang Lu).

weights from Neolithic Central Europe. Early loom types are also known in China, such as the back-strap loom of the Liangzhu culture (Zhao 1992), and there are still more in later periods, as evidenced by finds recovered from tombs 1 and 17 at Shizhaishan, Yunnan province (Vollmer 1977). All of these types of loom can be used to weave tabby or twill with one to three sheds. The weft is inserted manually, and they cannot produce programmed patterns. Another weaving technology capable of including multiple weft systems using treadle-powered looms was also present at this period in China. This was the oblique framed treadle loom, designed for plain weave textile, the earliest evidence of which comes from a depiction on a glazed pottery model from the Eastern Han Dynasty, c. 100-200 AD (Zhao 1997).

Several scholars, such as Flanagan (1919), Crowfoot and Griffiths (1939), Kuhn (1995) and Riboud (1977), have attempted to explain Chinese weaving technology from the evidence of ancient texts and finds of patterned archaeological textiles. Many scholars, such as Needham (1988) and James (1986), attribute the invention of the pattern loom (Hu 1980; Tu 1983) or draw loom (Sun 1963; Gao \& Zhang 1997) to ancient China. There is on-going disagreement, however, as to how the technology of the Chinese-invented pattern loom should be defined, and whether or not it comprised a multi-treadle and multi-shaft loom or a draw loom. The four newly discovered loom models excavated in Laoguanshan finally provide an unequivocal answer to this question, revealing it to have been a loom of the multi-shaft type. Moreover, they reveal an innovation that scholars had not previously considered: the use of a treadle to power the loom, and a hook beam to select the pattern shaft.

The multi-shaft system is known solely from Chinese historical documents. In the early Han Dynasty, during the second century BC, the wife of Chen Baoguang wove patterned damask with 120 nie (metal sticks), which were probably pattern rods, suggesting the use of pattern shafts (Cheng \& Cheng 1993). Later, during the Three Kingdoms period in the

(C) Antiquity Publications Ltd, 2017 
third century AD, a pattern loom for damask weave with either 50 treadles and 50 shafts, or 60 treadles and 60 shafts, was in use at Fufeng (Wang 2009), near present-day Xi'an. Both
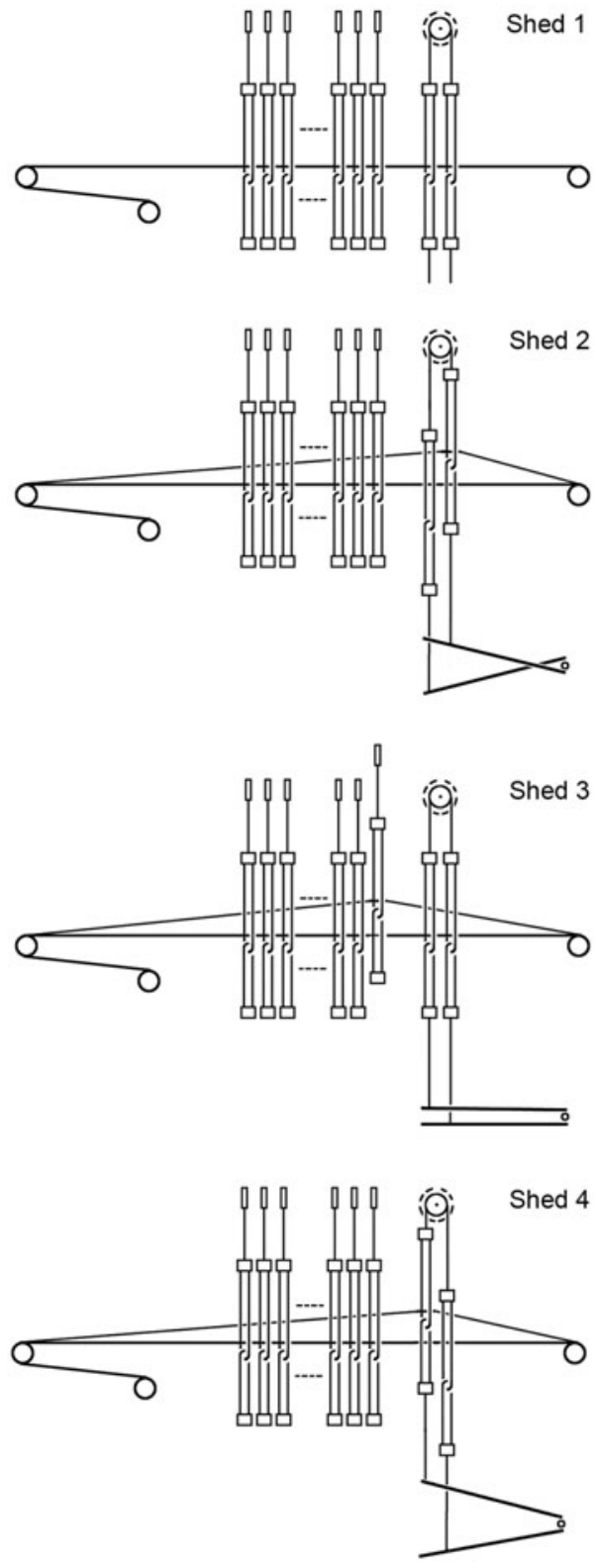

Figure 11. Shedding process of L.186. Four sheds (sheds 1-4) are formed step by step to carry out a weave unit. The sequence is repeated until pattern shaft 24 is listed for shed 48, which marks the end of one weave repetition (drawing by Bo Long).

(C) Antiquity Publications Ltd, 2017 of these examples, the Baoguang loom and the Fufeng loom, belong to the shaft pattern loom type.

Moreover, the axle treadle is also attested in later Han Dynasty contexts, as shown by an oblique treadle loom for plain weave, from the first or second century AD. This loom had two treadles on a pedal beam, connected to two arms at right angles from one another, on a single axle. One arm pulled the axle to lift the shaft and release the warp tension, and the other pushed the axle to release the shaft but press the warp (Zhao 1996). This system is also a linkage mechanism, similar to that used in the pattern loom(s) described from Laoguanshan.

Several textile terms described in the late Han Dynasty poem Jifu fu resemble components of this pattern loom, such as sheng for warp beam, $f u$ for cloth beam, $d a$ kuang for loom body, guang for shaft, zhou for treadle axle, tu er for cloth beam, gao lou for castle, $y u$ for shuttle and $l u l u$ for pulley (Xu 1999).

The Laoguanshan discovery suggests that the pattern loom was first invented in China in Chengdu, the ancient kindom of Shu. This city is known to have had an official jin silk workshop in the Qin and Han Dynasties from between the second century $\mathrm{BC}$ and the second century AD. This means that, in the kingdom of Shu at least, weavers must have used a pattern loom for weaving jin silk with warp-faced compound tabby. Together with these pattern loom models, other weaving-related tools and paraphernalia were recovered through excavation, including warping devices, a warping board, silk rewinders and weft winders, and also 15 painted figurines, including four male weavers and female weaving assistants in the act of warping, weft winding and rewinding. 
This find also provides relevant information about the proportions of both the model and the real loom based on the size of the human figurines. They were around $0.25 \mathrm{~m}$ tall, giving an approximate ratio of 1:6; this was subsequently used for our reconstruction of the Han hook-shaft pattern loom.

\section{Conclusion}

The discovery of these models of unique hook-shaft pattern looms sheds new light on the history of early technology and on the transmission of innovations in the second century BC. It pre-dates the previous earliest evidence for this weaving technology by several centuries, and represents the missing technological link responsible for the renowned Han Dynasty Shu jin silks, which are frequently found along the Silk Road, and were traded across Eurasia. The early date of the find suggests that it influenced the invention of the draw loom (see Zhao 2014). It also illustrates how Han Dynasty China exported not only spectacular qualities and patterns of silk to Central Asia and the Roman and late-Roman west, but also how weavers in this area of China used a different and more complex weaving technology than that documented anywhere else for the time.

This archaeological find is thus significant not only for the Chinese history of silk and textiles, but also for the global history of science and technology. At present, they are undoubtedly the earliest models of pattern looms in the world, and perfectly illustrate the superb Chinese technique of silk weaving. We believe that this shaft pattern loom was the basis for the invention of the draw loom, which was then introduced to the West (Persia, India and Europe), indicating that the Chinese silk pattern loom made a significant contribution to the subsequent development of world textile culture and weaving technology.

\section{Acknowledgements}

This project is supported by the Compass Plan, State Administration of Cultural Heritage, 2014. This was a joint project by more than seven institutes, and we thank the following people who have helped and contributed in various ways: Ziqiang Wang and Yang Zhou of the China National Silk Museum, who studied the archaeological loom models; Mingbin Li and Yang Li of Chengdu Museum who assisted the authors in measuring the loom models; Jialiang Lu of Zhejiang Sci-tech University, and Le Wang of Donghua University, who drew the images of reconstituted jin silks; Hui Liu of the Institute for the History of Natural Sciences, Chinese Academy of Sciences, who provided historical documents. We also would like to thank Karin Frei of the National Museum of Denmark for giving valuable suggestions and assistance in editing the manuscript.

\section{Glossary}

The following glossary is based on Warp and weft: a textile terminology by D.K. Burnham (1980). See also Figure 4.

Back-strap loom: a type of loom where tension to stretch the warp ends is applied by the weight of the weaver's body. One end is usually attached around the weaver's waist by a belt, and the other is fixed somewhere or held by the weaver's feet.

Cloth beam: the roller on which the cloth is wound as weaving proceeds. 
Counter shed: the shed opposite the natural shed. The counter shed is usually created by manipulation of a heddle rod.

Draw loom: a type of loom characterised by using pattern cords; it first appeared in the early Tang dynasty. Two persons are needed for weaving, with one manning the lower portion of the loom, and the other controlling the draw cords at a higher elevation.

Foundation shaft: pair of shafts that lift the warp ends, one for 1, 3, 5 and so on, and the other for 2, 4, 6 and so on, in order to make a tabby binding for the warp-faced compound weave.

Foundation weave: binding structure made of foundation shafts throughout the whole fabric.

Grille: two arrays of upright rods, standing on the loom castle, and containing the shaft bars that lift the pattern shafts.

Heddle/shaft heddle: a device (a thread harness in the case of the pattern looms described here) situated within the loom, with an eye through which warp ends are threaded. It is used to pull the upper and lower warp threads apart, thereby creating the shed.

Heddle rod: a rod with loops used on simple looms for making a shed opening. It lies in front of, or above, the warp, and is attached by loops to those warp threads that are at the back of the shed stick. By the raising of the heddle rod, these threads are brought forward to form a counter shed to that made by the shed stick. The number of heddle rods may be increased for patterning purposes.

Hook beam: horizontal beam, rested upon two sliding frames, with two hooks to lift the shaft bar.

Loom castle: the support frame that stands upon the loom body to contain and facilitate the grille and shaft heddles.

Natural shed: with many simple looms, a natural shed exists when the loom is at rest. This is usually due to the position of the shed stick, but may also be because of the position of a fixed heddle rod.

Pattern shaft: a series of shafts that lift warp ends to create the pattern on a foundation weave.

Pattern rods: sticks to pick up the warps that are arranged on top of the fabric to form the pattern.

Pick: a single passage of the shuttle carrying one or more weft threads through the shed.

Shaft: a group of heddles fixed side by side in order that they may be moved together at the same time. Most commonly, a shaft consists of a series of heddles between two horizontal bars. 
Shed: the opening in the warp that permits passage of the shuttle and thereby the pick.

Shed stick: stick threaded between stretched warp ends, creating an opening, or shed, through which the weft is passed.

Shuttle: a device to help store and deliver yarn as weft.

Tabby/tabby binding: a plain weave structure in which the weft and warp threads form a criss-cross pattern.

Twill: a textile weave with a diagonal pattern created by offset rows of weft.

Warp: the longitudinal threads of a textile as arranged on the loom.

Warp beam: the roller on which the warp is wound in preparation for weaving.

Warp-faced compound tabby/weave: a weave made using a warp comprising two or more different series and one weft. Alternate wefts serve to separate the series of warp ends so that only one appears on the face, while the other(s) is kept on the reverse face. The remaining wefts bind the warp ends in a tabby structure.

Weft: transverse threads of a textile weave that are passed through the sheds.

Whip roll: the roller at the back of the loom, used to guide the warp ends on their way to the heddle.

\section{References}

The Archaeological Research Group of the Shanghai Textile Research Institute and the Shanghai Silk Industry Corporation. 1980. A study of the textile fabrics unearthed from Han tomb no. 1 at Mawangtui in Changsha. Beijing: Wenwu.

Broudy, E. 1979. The book of looms: a history of the handloom from ancient times to the present. Providence (RI): Brown University Press.

Burnham, D.K. 1980. Warp and weft: a textile terminology. Toronto: Royal Ontario Museum.

Chen, Z.Y. 1993. Han tomb no. 168 at Fenghuangshan, Jiangling. Journal of Archaeology in China 4: 455-513.

Chengdu Institute of Archaeology and Jinzhou Conservation Center for Cultural Heritage. 2014. Archaeological report of Han tombs at Laoguanshan, Tianhuizhen, Chengdu, Sichuan. Archaeology 7: 59-70.

Cheng, L. \& Z.C. Cheng. 1993. Xi Jing Za Ji. Guiyang: Guizhou.

Crowfoot, G.M. \& J. Griffiths. 1939. Coptic textiles in two-faced weave with pattern in reverse. Journal of Egyptian Archaeology 25: 40-47.
Flanagan, J.F. 1919. The origin of the drawloom used in the making of early Byzantine silks. The Burlington Magazine for Connoisseurs 35: 167-72.

GAO, H.Y. \& P.G. ZHANG. 1997. A research of development of silk weaving machinery in ancient China. Beijing: China Textile.

Hu, Y.D., J.P. WANG, T. YU, X.H. XIAO, J.F. WANG, Y.Y. Chen \& Z.Y. Zhou. 1980. The development of Shu silk loom from a point of view of Dingqiao loom: a field research report on the multi-treadle and multi-shaft loom. Newsletter of History of Textile Science and Technology in China 1: 50-62.

James, J.M. 1986. Silk, China and the drawloom. Archaeology 39: 64-65.

KunN, D. 1995. Silk weaving in ancient China: from geometric figures to patterns of pictorial likeness. Chinese Science 12: 77-114.

Needham, J. 1988. Science and civilisation in China. Cambridge: Cambridge University Press.

Riвoud, K. 1977. A detailed study of the figured silk with birds, rocks and trees from the Han Dynasty. Bulletin de Liaison, CIETA 45: 51-60.

Sun, Y.T. 1963. The development of textile technology during the Warring States period to Qin and Han Dynasties. Research on History 3: 143-73. 
Tu, H.X. 1983. Research and reproduction of silk textiles from the Warring States Period. Unpublished PhD dissertation, Donghua Univesity.

Vollmer, J.E. 1977. Archaeological and ethnological considerations of the foot-braced body tension loom. Studies in Textile History: 343-54. Toronto: Royal Ontario Museum.

WANG, K.R. 2009. San Guo Zhi [The records of three kingdoms]. Shenyang: Northern United.

Xu, Z.S. 1999. K.J. Yan's Quan Hou Han Wen [The collected works of the Eastern Han Dynasty]. Beijing: Commercial.

Zнао, F. 1992. Reconstruction of back-strap loom of Liangzhu. Southeast Culture 2: 108-11.
- 1996. Reproduction of Han Dynasty oblique treadle loom. Cultural Relics 5: 87-95.

- 1997. Reconstruction of axle-treadle loom in Han Dynasty. Journal of China Textile University 4: 60-65.

- 1999. Treasures in silk: an illustrated history of Chinese textiles. Hong Kong: ISAT/Costume Squad.

- 2014. The development of pattern weaving technology through textile exchange along the Silk Road, in M-L. Nosch, F. Zhao \& L. Varadarajan. (ed.) Global textile encounters (Ancient Textile Series 20): 49-64. Oxford: Oxbow.

Received: 20 September 2015; Accepted: 22 December 2015; Revised: 4 January 2016 